\title{
Health-Related Quality of Life (HRQoL) of Tuberculosis (TB) Patients in Akwa Ibom State, Nigeria
}

\author{
Anne E. Asuquo1, Benjamin Thumamo Pokam²*, Anthonia Adindu ${ }^{3}$, Emmanuel Ibeneme1, \\ Valerie Obot $^{4}$ \\ ${ }^{1}$ Department of Medical Laboratory Science, University of Calabar, Calabar, Nigeria \\ ${ }^{2}$ Department of Medical Laboratory Science, University of Buea, Buea, Cameroon \\ ${ }^{3}$ Department of Public Health, University of Calabar, Calabar, Nigeria \\ ${ }^{4}$ Ministry of Health, Akwa Ibom State, Nigeria \\ Email: thumamo@yahoo.fr
}

Received 1 November 2014; revised 4 December 2014; accepted 18 December 2014

Academic Editor: Mark Spigelman, Department of Microbiology and Molecular Genetics, Hebrew University, Israel

Copyright (C) 2014 by authors and Scientific Research Publishing Inc.

This work is licensed under the Creative Commons Attribution International License (CC BY).

http://creativecommons.org/licenses/by/4.0/

(c) (i) Open Access

\section{Abstract}

Background: Efforts to combat tuberculosis in Nigeria focus on evaluation of strategies for treatment and prevention, with little attention paid to the impact of the burden of illness and its therapy on the HRQoL of TB patients. This study evaluated the quality of life (QoL) of TB patients in relation to their financial, psychological and social well-being. Method: In 2011, following an active case finding for TB in Akwa Ibom State of Nigeria, a structured questionnaire for evaluating HRQoL was distributed to TB patients who had been on treatment in four DOTs centres of the state for at least three months. The questions were to elicit responses that conveyed the respondents' perspective of the disease. One hundred and eight TB patients (54 males and 54 females) aged 15 80 years were studied. Results: Negative emotions including fear, frustration and worry characterized the reactions of all subjects following news of their diagnosis with TB. However, following treatment, $62 \%$ of subjects expressed high expectation of being cured. Inability to continue functioning in their roles at home or as heads of households was recorded in $48.1 \%(52 / 108)$ and $59 \%$ $(23 / 39)$ of respondents respectively and contributed to the negative emotions expressed above. Lack of basic supplies such as food and finances to meet personal and family needs constituted the most important socio-economic challenges. Socio-economic status of respondents revealed that $61 \%$ had no regular means of income with at least $94 \%$ earning less than \$50 (8000 naira) a month. Subsistent farmers and petty traders constituted more than $66 \%$ of the respondents: $98 \%$ ob-

\footnotetext{
"Corresponding author.

How to cite this paper: Asuquo, A.E., Pokam, B.T., Adindu, A., Ibeneme, E. and Obot, V. (2014) Health-Related Quality of Life (HRQoL) of Tuberculosis (TB) Patients in Akwa Ibom State, Nigeria. Journal of Tuberculosis Research, 2, 199-206. 
tained less than or equivalent of high school education. Socially, all health workers and $87 \%$ of family members were sympathetic and supportive compared to friends, with $42 \%$ exhibiting stigmatization. The most frequent forms of support from family members were financial $(25 \%)$ and provision of food (37\%). Up to $28 \%$ were regularly prompted by family to take their medication. Conclusion: In the midst of obvious socio-economic challenges confronting TB patients in this study, the initial negative emotions declined following the supportive roles of mainly health care workers and family members. Patients were optimistic of achieving cure at the end of the treatment.

\section{Keywords}

Tuberculosis, Quality of Life, Socio-Economic Impact, Akwa Ibom State, Nigeria

\section{Introduction}

Tuberculosis is a disease with social implications due to the stigma attached to it. It has been seen that apart from physical symptoms, TB patients face various problems that are social and economic in nature. Therefore, for a comprehensive assessment of patients' health status, it is essential to consider the overall impact of TB on health and patients' perception of well-being, besides routine clinical, radiological and bacteriological assessments [1].

According to the World Health Organization, health is defined as a state of complete physical, mental and social well-being and not a mere absence of disease or infirmity. The impact of any disease, especially a chronic illness like tuberculosis, on an individual patient is therefore often all-encompassing, affecting not only his physical health but also his psychological, economic and social well-being [2]. Although laboratories or clinical tests provide important information regarding the disease, it is often impossible to separate the disease from the individual's personal and social context, especially in chronic and progressive diseases [3].

Nigeria ranks 11 th among the 22 high TB burden countries. Reports from the recently concluded National TB prevalence survey put the prevalence at 570,000 (incidence at 140,000) and the rate at 326/100,000 population. This is about three times higher than the current World Health Organization estimates and five times more than the current programme notification figures [4]. Some studies have shown that vulnerability of the patients to socio-economic and psychological domains can be studied by measuring the HRQoL of the patients [5]-[10]. Though the data on formal assessment of HRQoL in patients of tuberculosis are rather sparse [2], TB patients have been shown to have significantly lower mean scores than the controls for overall QoL and its domains [1]. The worst affected were physical domain followed by the psychological domain. TB does equally affect the general health perception and social role functioning of patients [11] [12].

Unfortunately, little attention has been paid to the impact of the burden of illness and its therapy on the HRQoL of patients with tuberculosis in the country. The HRQoL of TB patients in this study was evaluated with the aim of highlighting the impact of the disease on the overall well-being of participants, an often neglected aspect of health.

\section{Patients and Methods}

Following an active case finding of TB patients carried out in Akwa Ibom State of Nigeria in 2011, a structured questionnaire was administered to 120 patients undergoing Directly Observed Therapy short course (DOTS), out of which 108 (54 females and 54 males) responded. The study participants resided in four Local Government Areas of Oron, Ikot Ekpene, Ibeno and Oruk Anam. Non-TB subjects were not recruited into this study. Questionnaire administrators explained purpose of the study to patients, confidentiality of data generated and their freedom to withdraw from the study anytime. The questionnaire mainly evaluated the demographic, social, psychological and economic aspects of active TB patients on DOTS, and each respondent gave verbal informed consent. Completed questionnaires were examined for error, and clarification obtained from respondents. All data were analysed using SPSS statistical software.

\section{Results}

The demographic and economic characteristics of respondents are shown in Table 1. Over half 59 (54.6\%) of 
Table 1. Demography and economic characteristics of respondents.

\begin{tabular}{|c|c|c|}
\hline Socio-demographic and economic characteristics & $\mathrm{n}$ & $\%$ \\
\hline Gender & 108 & \\
\hline Male & 54 & 50 \\
\hline Female & 54 & 50 \\
\hline Age & 108 & \\
\hline $15-24$ & 14 & 13 \\
\hline $25-34$ & 28 & 26 \\
\hline $35-44$ & 31 & 28.7 \\
\hline $45-54$ & 15 & 13.8 \\
\hline $55-64$ & 3 & 2.7 \\
\hline$>64$ & 8 & 7.4 \\
\hline No response & 9 & 8.3 \\
\hline Marital status & 108 & \\
\hline Married & 76 & 70.4 \\
\hline Single & 20 & 18.5 \\
\hline Widow & 9 & 8.3 \\
\hline Divorce & 2 & 1.9 \\
\hline Separated & 1 & 0.9 \\
\hline Level of education & 108 & \\
\hline Completed primary school & 68 & 63 \\
\hline Completed secondary school & 27 & 25 \\
\hline Completed university & 6 & 5.5 \\
\hline No response & 7 & 6.5 \\
\hline Occupation & 108 & \\
\hline Civil servants & 4 & 3.7 \\
\hline Farmers & 36 & 33.3 \\
\hline Students & 9 & 8.3 \\
\hline Traders & 36 & 33.3 \\
\hline Other occupations & 13 & 12.0 \\
\hline No response & 10 & 9.3 \\
\hline Head of household & 108 & \\
\hline Heads & 39 & 36.1 \\
\hline Not heads & 60 & 55.5 \\
\hline No response & 9 & 8.3 \\
\hline Income & 108 & \\
\hline No income & 66 & 61.1 \\
\hline$\$ 500$ to $2000(\$ 3.1-12.5)$ & 25 & 23.1 \\
\hline$\$ 2500$ to $4000(\$ 12.5-28.1)$ & 4 & 3.7 \\
\hline$\$ 4500$ to $6000(\$ 28.1-37.5)$ & 7 & 6.5 \\
\hline$\$ 6500$ to $8000(\$ 40.6-50)$ & 0 & 0 \\
\hline$\$ 8500$ to $10,000(\$ 53.1-62.5)$ & 1 & 0.9 \\
\hline Over $\$ 10,000(>\$ 62.5)$ & 5 & 4.6 \\
\hline
\end{tabular}


respondents were aged between 25 and 44 years, with the mean age of 38.9 years, and there were more females $35(32.4 \%)$ than males $24(22.2 \%)$ in this category of respondents. Of the 96 responses on marital status, 76 $(70 \%)$ were married while $20(18.5 \%)$ were single. Of the 101 respondents who provided information on their educational qualification, $68(63 \%)$ and $27(25 \%)$ respectively completed primary and secondary education, while $6(5.5 \%)$ completed tertiary education. Farmers $36(33.3 \%)$, traders $36(33.3 \%)$ and students $9(8.3 \%)$ were the most prominent occupations categories encountered in the study. Thirty nine (36.1\%) respondents were heads of households and nearly all respondents $105(97.2 \%)$ said family members were aware of their illness (TB). Monthly income of respondents ranged from 66 (61.1\%) with no regular means of income to only 5 (4.6\%) with an income of over 10,000 naira $(>\$ 62.5)$. Negative emotions including fear, frustration and worry characterized the reactions of all subjects following news of their diagnosis with TB (Figure 1). Although these negative feelings significantly $(p=0.045)$ impacted on the respondents apprehension on getting cured, gender did not significantly influence such pessimism $(\mathrm{p}=0.32)$. However, following treatment, $62 \%$ of subjects expressed high expectation of being cured based on the improvement of their general well-being. Responses of 86 of 108 study participants showed that all health workers, as well as $87 \%$ family members were sympathetic and supportive compared to friends, with $42 \%$ (36/86 aware of the status) exhibiting stigmatization (Figure 2). The major challenges encountered by the patients were socioeconomic and included lack of basic supplies such as food and finances to meet personal and family needs (Figure 3). However, family support appeared to have helped to ameliorate those challenges for some of the patients. Specifically, $37 \%$ of family support was in form of food supplies and finance $(25 \%$ ), while about $28 \%$ contributed to patients' compliance to medication by regularly reminding them to take their medication (Table 2). Inability to continue functioning in their roles at home was recorded among $48.1 \%(52 / 108)$ of the respondents, and a significant proportion in this category $(76 \%)$ felt they will not get cured at diagnosis $(p=0.00)$. About 59\% (23/39) identified as heads of household were equally unable to carry out their responsibility at home $(\mathrm{p}=0.07)$ (Figure 4). Besides $\mathrm{TB}$, the respondents concomitantly faced other health challenges, with 33 (30.6\%) suffering from malaria, 9 (8.3\%) HIV/AIDS, 8 (7.4\%) malnutrition, and 7 (6.5\%) typhoid fever (Figure 5).

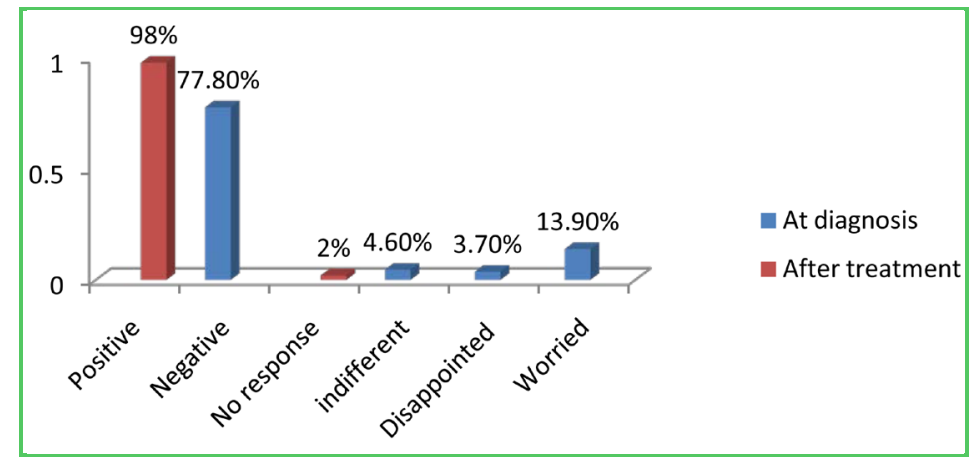

Figure 1. Respondents' feelings at diagnosis and after treatment.

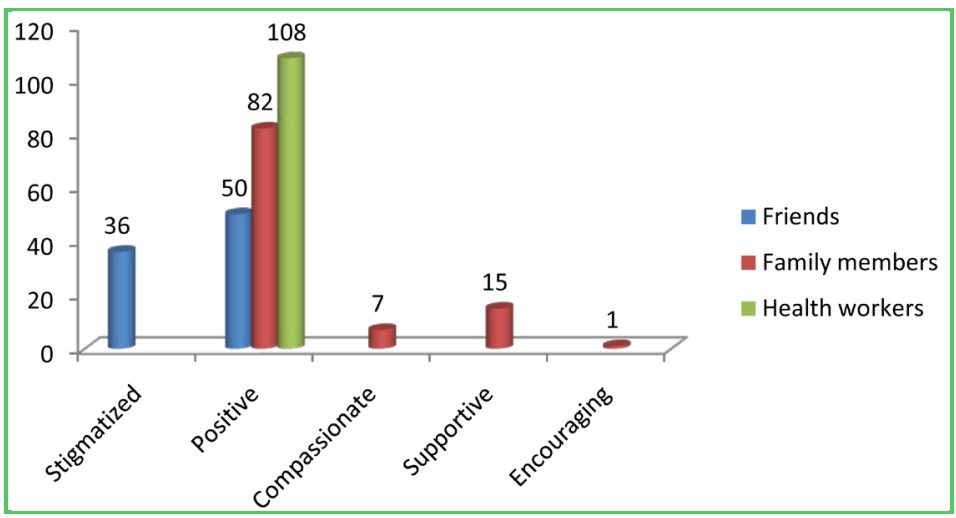

Figure 2. Treatment attitude of friends, family members and health workers aware of TB status. 


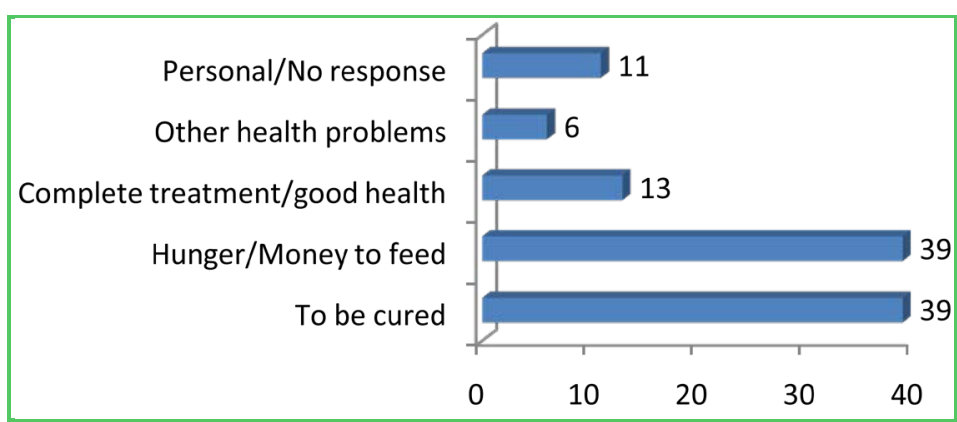

Figure 3. Major concern/worries of respondents after diagnosis.

Table 2. Support types from family members.

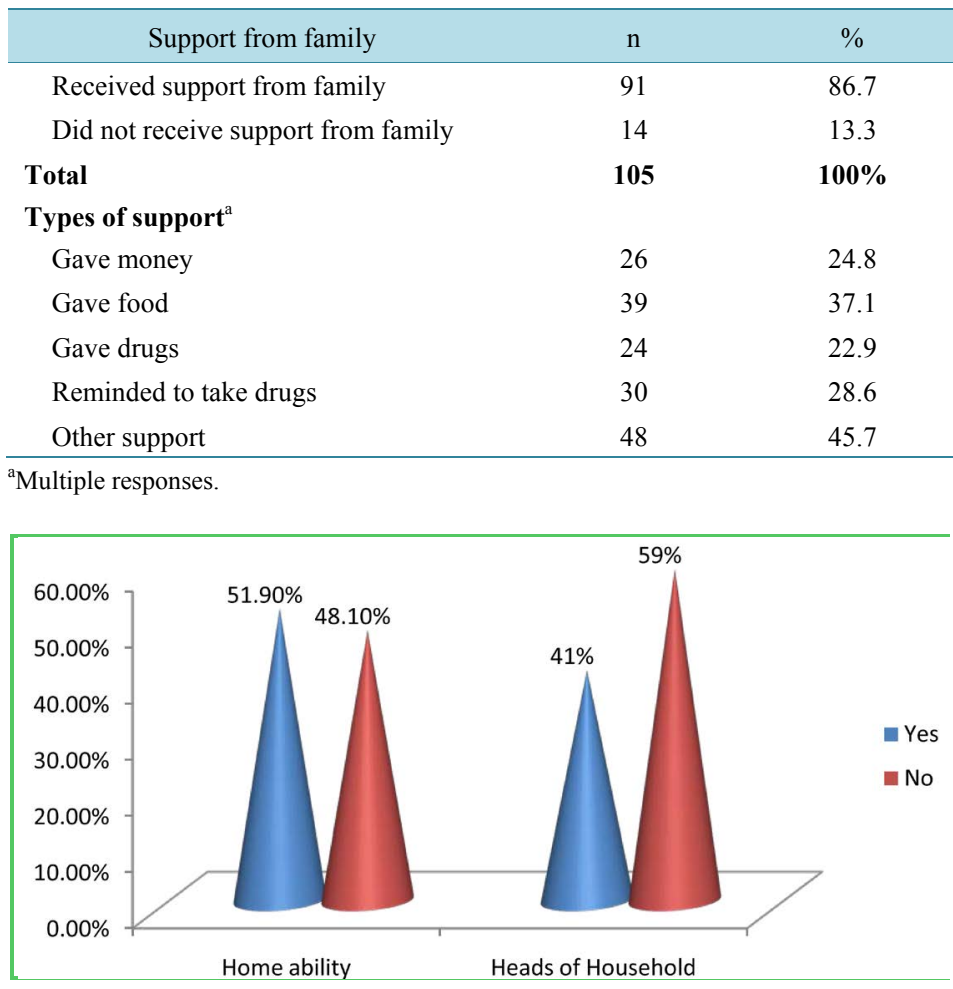

Figure 4. Ability to carry out responsibility at home by respondents and by heads of household.

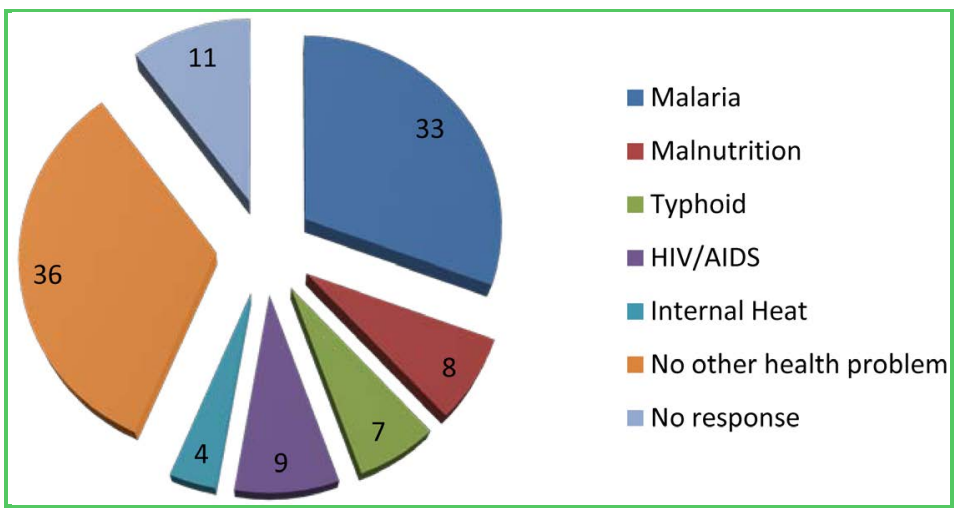

Figure 5. Other health problems concomitantly faced by respondents. 


\section{Discussion}

Although effective therapy has long been available in the cure of tuberculosis, many aspects of TB along with its treatment could potentially compromise patients' HRQoL. Furthermore, several studies have shown that TB has a substantial and encompassing impact on patients' QoL [13]. There has been however almost no effort, especially in Africa to investigate the TB patients' QoL.

The impaired HRQoL experienced by TB patients may be a reflection of socio-demographic or socio-economic status and other underlying co-morbid conditions besides TB and its treatment [13]. Patients in this study also had other health challenges which may not be unconnected with a poor QoL. Duyan et al. [14] found that better HRQoL was correlated with higher income, higher education, better housing conditions, better social security, and closer relationships with family members and friends. In this study, TB patients had both low income and low education with only about $6 \%$ of them completing tertiary education. Financial well-being of individuals and families is also affected by tuberculosis and is often related to impairment in role functioning [2]. Some heads of families in this study were unable to continue to perform their roles as heads of their households. Having a tuberculosis patient in the family increases the workload on the primary caregivers, thereby reducing their capacity to generate income and care for other family members [15]. In a related study in India, almost a third of TB patients were unable to provide basic necessities including food, clothing and books for their children [16]. Many children of parents with tuberculosis are even forced to discontinue their education and take on jobs in order to contribute to the finances of the family. The African context of solidarity as shown in this study by the various forms of support especially from family members providing food, drugs and money might have lessened this social impact.

The discriminatory attitude of friends towards TB patients in this study is not uncommon. It has been shown in some communities that TB patients are perceived as a source of infection and the resultant social rejection and isolation leads to a long-term impairment on patients' psychosocial well-being [11] [17]-[21].

Many TB patients have been shown to experience negative emotions, such as anxiety and fear [11] [22]. Most patients are worried, frustrated, or disappointed by the diagnosis, and almost a quarter do not initially accept their diagnosis [17] [23] [24]. These negative emotions generally decline during the course of successful antitubercular therapy [23]. The negative emotions of fear, anxiety and frustration in our study at the time of diagnosis and early stage of the disease declined considerably after treatment. Some of the positive emotions expressed by respondents included well-being and happiness. This positive outcome may not be unconnected with the attitude of family members and health care workers as shown in the responses of the TB patients. However, some studies have shown unfriendly health care workers that made some patients feel frustrated, threatened, unwelcome, or uncomfortable [21] [25]. In some situations, even following discharge from health facility, many patients are not received back into their homes [26].

Several studies have shown that treatment with anti-TB drugs improves patients' HRQoL, resulting in rapid turnaround on the physical health [22]. Impairment on mental well-being, however, tended to persist for a longer period [12] [27]. Nonetheless, comparing the HRQoL of TB patients who had completed treatment with the general population, some authors observed that the former remained poor [12] [22] [28] [29]. The clinical burden of the disease and the side-effects sequel to its management often extend beyond the duration of treatment. All these aspects have a huge impact on the overall well-being of the patient and the burden of these factors can equal and even exceed the physical impact of illness [30].

\section{Conclusion}

In addition to clinical symptoms, tuberculosis patients have to deal with social, financial and psychological problems, all of which have huge negative impact on them. Poverty, stigmatization and concomitant infections in a malarial endemic region coupled with the HIV/AIDS burden faced by some TB patients in this study may have constituted a cocktail of despair. Despite all these challenges, support from health care workers and especially from family members greatly impacted positively on their attitude and their high expectation of achieving cure at the end of treatment. The negative emotions that characterized their initial reaction to the diagnosis were replaced by positive attitudes following treatment.

\section{Acknowledgements}

The authors are grateful to the patients for their willingness to participate in this study. 


\section{Conflict of Interest}

None to declare.

\section{References}

[1] Dhuria, M., Sharma, N. and Ingle, G.K. (2008) Impact of Tuberculosis on the Quality of Life. Indian Journal of Community Medicine, 33, 58-59. http://dx.doi.org/10.4103/0970-0218.39249

[2] Aggarwal, A.N. (2010) Health Related Quality of Life: A Neglected Aspect of Pulmonary Tuberculosis. Lung India, 27, 1-3. http://dx.doi.org/10.4103/0970-2113.59259

[3] Bowling, A. (1995) Measuring Disease: A Review of Disease-Specific Quality of Life Measurement Scales. Open University Press, Buckingham.

[4] WHO (2014) Global TB Report, 2014. WHO, Geneva.

[5] Atiq, M., Gill, M.L. and Khokhar, N. (2004) Quality of Life Assessment in Pakistani Patients with Chronic Liver Disease. Journal of Pakistan Medical Association, 54, 113-115.

[6] Awan, M.S., Waqas, M., Aslam, M.A. and Sarwar, M. (2011) Measurement of SF-6D Utility among Patients with Active Tuberculosis. Global Journal of Health Science, 3, 203-208. http://dx.doi.org/10.5539/gjhs.v3n1p203

[7] Awan, M.S., Waqas, M., Aslam, M.A. and Abbas, F. (2011) Health Related Quality of Life Assessment in Patients with Hepatitis: A Case of Pakistan. Interdisciplinary Journal of Contemporary Research in Business, 1, 1259-1268.

[8] Awan, M.S., Waqas, M., Ali, M. and Aslam, M.A. (2011) Status of Health Related Quality of Life between HBV and HCV Patients of Pakistan. International Journal of Business and Social Science, 2, 213-220.

[9] Brazier, J.E. and Roberts, J.R. (2004) The Estimation of a Preference-Based Index from the SF-12. Medical Care, 42, 851-859. http://dx.doi.org/10.1097/01.mlr.0000135827.18610.0d

[10] Dhingra, V.K. and Rajpal, S. (2003) Health Related Quality of Life (HRQL) Scoring in Tuberculosis. Indian Journal of Tuberculosis, 50, 99-104.

[11] Hansel, N.N., Wu, A.W., Chang, B. and Diette, G.B. (2004) Quality of Life in Tuberculosis: Patient and Provider Perspectives. Quality of Life Research, 13, 639-652. http://dx.doi.org/10.1023/B:QURE.0000021317.12945.f0

[12] Chamla, D. (2004) The Assessment of Patients' Health-Related Quality of Life during Tuberculosis Treatment in Wuhan, China. International Journal of Tuberculosis and Lung Disease, 8, 1100-1106.

[13] Guo, N., Marra, F. and Marra, C.A. (2009) Measuring Health-Related Quality of Life in Tuberculosis: A Systematic Review. Health and Quality of Life Outcomes, 7, 14. http://dx.doi.org/10.1186/1477-7525-7-14

[14] Duyan, V., Kurt, B., Aktas, Z., Duyan, G.C. and Kulkul, D.O. (2005) Relationship between Quality of Life and Characteristics of Patients Hospitalised with Tuberculosis. International Journal of Tuberculosis and Lung Disease, 9 , 1361-1366.

[15] Kamolratanakul, P., Sawert, H., Kongsin, S., Lertmaharit, S., Sriwongsa, J., Na-Songkhla, S., et al. (1999) Economic Impact of Tuberculosis at the Household Level. International Journal of Tuberculosis and Lung Disease, 3, 596-602.

[16] Rajeswari, R., Balasubramanian, R., Muniyandi, M., Geetharamani, S., Thresa, X. and Venkatesan, P. (1999) SocioEconomic Impact of Tuberculosis on Patients and Family in India. International Journal of Tuberculosis and Lung Disease, 3, 869-877.

[17] Liefooghe, R., Michiels, N., Habib, S., Moran, M.B. and De Muynck, A. (1995) Perception and Social Consequences of Tuberculosis: A Focus Group Study of Tuberculosis Patients in Sialkot, Pakistan. Social Science \& Medicine, 41, 1685-1692. http://dx.doi.org/10.1016/0277-9536(95)00129-U

[18] Kelly, P. (1999) Isolation and Stigma: The Experience of Patients with Active Tuberculosis. Journal of Community Health Nursing, 16, 233-241. http://dx.doi.org/10.1207/S15327655JCHN1604_3

[19] Long, N.H., Johansson, E., Diwan, V.K. and Winkvist, A. (2001) Fear and Social Isolation as Consequences of Tuberculosis in VietNam: A Gender Analysis. Health Policy, 58, 69-81. http://dx.doi.org/10.1016/S0168-8510(01)00143-9

[20] Macq, J., Solis, A., Martinez, G., Martiny, P. and Dujardin, B. (2005) An Exploration of the Social Stigma of Tuberculosis in Five "Municipios" of Nicaragua to Reflect on Local Interventions. Health Policy, 74, 205-217. http://dx.doi.org/10.1016/j.healthpol.2005.01.003

[21] Marra, C.A., Marra, F., Cox, V.C., Palepu, A. and Fitzgerald, J.M. (2004) Factors Influencing Quality of Life in Patients with Active Tuberculosis. Health and Quality of Life Outcomes, 2, 58. http://dx.doi.org/10.1186/1477-7525-2-58

[22] Marra, C.A., Marra, F., Colley, L., Moadebi, S., Elwood, R.K. and Fitzgerald, J.M. (2008) Health-Related Quality of Life Trajectories among Adults with Tuberculosis: Differences between Latent and Active Infection. CHEST Journal, 133, 396-403. http://dx.doi.org/10.1378/chest.07-1494 
[23] Rajeswari, R., Muniyandi, M., Balasubramanian, R. and Narayanan, P.R. (2005) Perceptions of Tuberculosis Patients about Their Physical, Mental and Social Well-Being: A Field Report from South India. Social Science \& Medicine, 60, 1845-1853. http://dx.doi.org/10.1016/j.socscimed.2004.08.024

[24] Khan, A., Walley, J., Newell, J. and Imdad, N. (2000) Tuberculosis in Pakistan: Socio-Cultural Constraints and Opportunities in Treatment. Social Science \& Medicine, 50, 247-254. http://dx.doi.org/10.1016/S0277-9536(99)00279-8

[25] Barnhoorn, F. and Adriaanse, H. (1992) In Search of Factors Responsible for Noncompliance among Tuberculosis Patients in Wardha District, India. Social Science \& Medicine, 34, 291-306. http://dx.doi.org/10.1016/0277-9536(92)90271-Q

[26] Rubel, A.J. and Garro, L.C. (1992) Social and Cultural Factors in the Successful Control of Tuberculosis. Public Health Reports, 107, 626-636.

[27] Dhingra, V.K. and Rajpal, S. (2005) Health Related Quality of Life (HRQL) Scoring (DR-12 Score) in TuberculosisAdditional Evaluative Tool under DOTS. The Journal of Communicable Diseases, 37, 261-268.

[28] Dion, M.J., Tousignant, P., Bourbeau, J., Menzies, D. and Schwartzman, K. (2004) Feasibility and Reliability of Health-Related Quality of Life Measurements among Tuberculosis Patients. Quality of Life Research, 13, 653-665. http://dx.doi.org/10.1023/B:QURE.0000021320.89524.64

[29] Dion, M.J., Tousignant, P., Bourbeau, J., Menzies, D. and Schwartzman, K. (2002) Measurement of Health Preferences among Patients with Tuberculous Infection and Disease. Medical Decision Making, 22, 102-114. http://dx.doi.org/10.1177/027298902237706

[30] Cassileth, B.R., Lusk, E.J., Strouse, T.B., Miller, D.S., Brown, L.L., Cross, P.A., et al. (1984) Psychosocial Status in Chronic Illness: A Comparative Analysis of Six Diagnostic Groups. The New England Journal of Medicine, 311, 506511. http://dx.doi.org/10.1056/NEJM198408233110805 
Scientific Research Publishing (SCIRP) is one of the largest Open Access journal publishers. It is currently publishing more than 200 open access, online, peer-reviewed journals covering a wide range of academic disciplines. SCIRP serves the worldwide academic communities and contributes to the progress and application of science with its publication.

Other selected journals from SCIRP are listed as below. Submit your manuscript to us via either submit@scirp.org or Online Submission Portal.
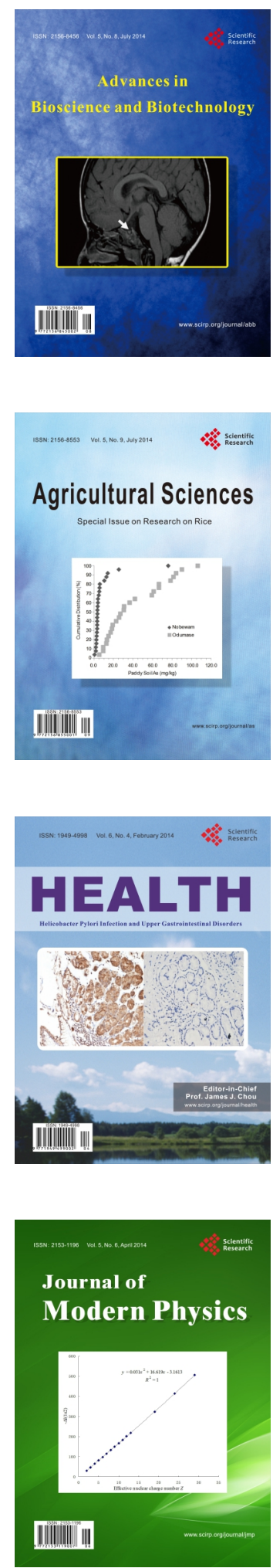
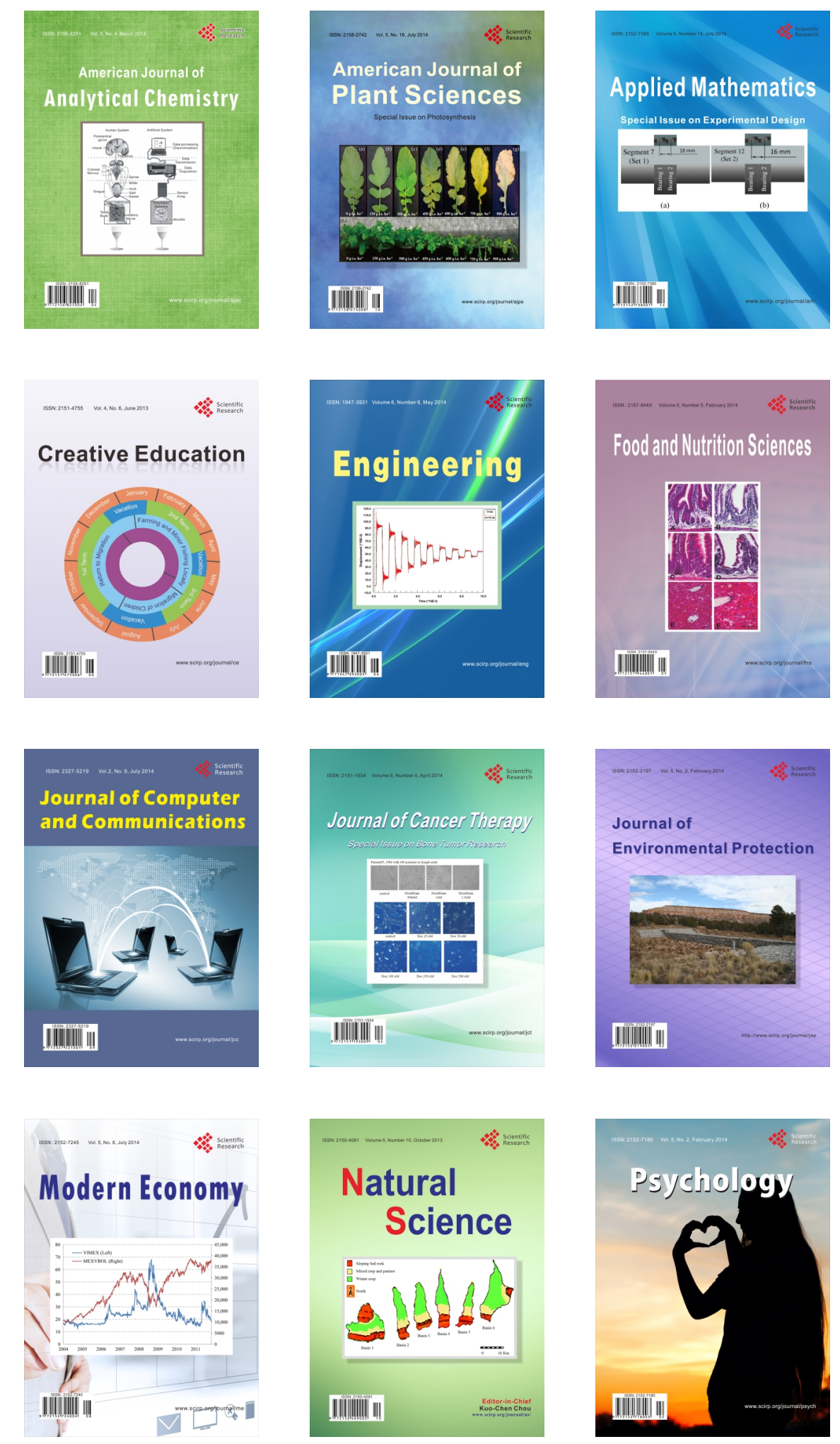